The Journal of Animal \& Plant Sciences, 30(5): 2020, Page: 1187-1193

ISSN (print): 1018-7081; ISSN (online): 2309-8694

\title{
INOCULATION OF BRASSICA NAPUS L. GENOTYPES WITH ENDOPHYTIC BACTERIA PROMOTE GROWTH AND ALLEVIATE CADMIUM TOXICITY
}

\author{
A. U. Shah ${ }^{1}$, H. Rajab ${ }^{1}$, A. Jalal ${ }^{1}$, M. Ajmal ${ }^{1}$, S. A. K. Bangash ${ }^{1}$, D. Ahmad ${ }^{1}$ and M. S. Khan ${ }^{1, *}$ \\ ${ }^{1}$ Institute of Biotechnology and Genetic Engineering, The University of Agriculture Peshawar, Khyber Pakhtunkhwa, \\ Pakistan \\ *Corresponding author Email address: sayyar@aup.edu.pk
}

\begin{abstract}
Cadmium is a non-essential heavy metal that is highly toxic for most of the plants, even at low concentrations. Cadmium tolerant endophytic bacteria isolated from different sources have been effectively used for mitigating cadmium toxicity and plant growth promotion. In the present study, the potential of an endophytic bacterial strain known as Serratia sp. IU01, previously isolated from Solanum nigrum, was evaluated in terms of alleviating cadmium toxicity and promoting host plant growth. A significant increase in the biomass of two genotypes of Brassica napus L. exposed to different concentrations of cadmium was observed after three weeks inoculation with Serratia sp. IU01 compared to sole cadmium treated plants. High performance liquid chromatography (HPLC) analysis revealed the steady-levels of one of the key antioxidants, i.e., glutathione, were significantly higher in the sole cadmium treated plants compared to control plants. However, inoculation of the cadmium treated plants with the bacterial endophyte resulted in a significant reduction in glutathione contents compared to sole cadmium treated plants, which suggest the antioxidants released by the endophyte in the host environment have assisted the host plant in minimizing the magnitude of the resultant oxidative damage. The precursor of glutathione, i.e., cysteine, showed a similar pattern in the sole cadmium treated and inoculated plants. Our data suggested that inoculation of Brassica napus with the bacterial isolate Serratia sp. IU01, under cadmium stress provide a physiological advantage to the plants in terms of growth promotion and alleviating cadmium toxicity.
\end{abstract}

Key words: Brassica napus, endophytes, cadmium, tolerance, stress.

https://doi.org/10.36899/JAPS.2020.5.0136

Published online June 25, 2020

\section{INTRODUCTION}

Contamination of agricultural lands with heavy metals is a global concern having serious implications for the environment and human health (Ryan et al, 1982; Mazess and Barden 1991; Gairola et al. 1992). Among the abundant heavy metals, cadmium is highly toxic nonessential metal ions for growth and development, which can be readily taken up and transported to different plant parts (Benavides et al. 2005; Gratão et al. 2005). It is toxic to plant cells even at low concentrations, and leaf cadmium concentrations greater than 5-10 $\mu \mathrm{g} \mathrm{g}^{-1}$ dry matter are toxic to most plants (White and Brown, 2010) with the exception of some plant ecotypes of few species which can grow on soils with high cadmium concentration. Cadmium accumulation in plants results in the inhibition of photosynthesis and degradation of chlorophyll contents, which ultimately leads to stunted plant growth. It changes the redox capability of the cell, producing ROS (reactive oxygen species), causing oxidative harm to cell membranes and related biomolecules (Cahoon et al., 2015).

Plant endophytic bacteria associate themselves with the host plants in a symbiotic/mutualistic relationship (Dudeja et al., 2012), and can provide a physiological advantage to their host plants in terms of growth promotion and protection against various forms of biotic and abiotic stresses (Lehtonen et al., 2006; Brader et al., 2014). They are well known for their potential to enhance plant growth via different direct or indirect mechanisms, and their role in the protection of their host against various forms of biotic and abiotic stresses have been well documented. Many reports have demonstrated that some of the hyper-accumulator plants, including Solanum nigrum L. harbor special endophytes that can tolerate higher concentrations of heavy metals such as cadmium (Chen et al., 2014). A number of cadmium accumulator endophytes have been isolated from Solanum nigrum L. and subsequently applied to alleviate cadmium toxicity in different plant species (Chen et al., 2010; Xiao et al., 2010; Vinichuk et al., 2013; Ullah et al., 2019).

Plants have evolved mechanisms to manage oxidative imbalances via the induction of different endogenous enzymatic and non-enzymatic antioxidant defense responses. Endophytes complement the defense mechanism of the plants by releasing exogenous antioxidants that avert the accumulation of reactive oxygen species (ROS) and mitigate the oxidative stress (Khan et al., 2013). Production of a number of antioxidants by plants as well as by endophytes supports the plants under stressed conditions and detoxifies the 
heavy metals via different processes such as bio-sorption and bioaccumulation (Di Fiore and Del Gallo, 1995; Mosa et al., 2016). In addition to enzymatic and nonenzymatic antioxidants, endophytes synthesize a number of phytohormones such as gibberellins, indole-3-acetic acid (IAA), and cytokinins that promote host plant growth which ultimately leads to increased biomass and higher Cd accumulation (You et al., 2013; Khan et al., 2014). Since soil under natural conditions may contain a variety of different endophytic communities, therefore, the use of an inert medium such as sterile/autoclaved sand for the growth of the plants provides a suitable alternative to exclude the role of soil. B. napus is an important plant for phytoremediation purposes of heavy metals due to its high capability to grow at a fast rate, high biomass, and high tolerance to heavy metals. It is one of the most suitable phytoaccumulator plants that has been used in heavy metal contaminated areas to clean up the environment (Angelova et al., 2017). The reason for using this specific bacterial isolate was that it was shown earlier to enhance plant growth and cadmium tolerance in a closely related species (Ullah et al., 2019). The potential of an endophytic bacterium in terms of plant growth promotion, tolerance, and detoxification of cadmium was assessed by inoculating two genotypes of Brassica napus exposed to different concentrations of cadmium with this isolate. Moreover, plant biomass and thiol levels were analyzed to evaluate how cadmium and microbes affected the physiology of the plants.

\section{MATERIALS AND METHODS}

Plant Material: Seeds of Brassica napus (genotypes NIFA-1 and Abasyn-95) were kindly provided by Nuclear Institute for Food and Agriculture (NIFA), Peshawar Pakistan.

Seed Germination: Seeds of Brassica napus Genotypes were germinated over a thin layer of cotton in small cups with adequate water to moisten the seeds. The cups were placed in plastic tubs in the dark. After two days of sprouting of seeds, they were exposed to full light for further growth and germination. Seven days old plantlets were then shifted to cups with autoclaved sterile sand.

Experimental design, growth conditions, and biomass data for cadmium stress: The seven days old plantlets of genotype NIFA-1 were exposed to three different growth conditions. These include negative control plants which were simply grown on autoclaved sand (approx. 300 grams per pot), whereas one set of plants were treated with cadmium, and the last set of cadmium exposed plants were inoculated with the plant growth promoting (PGPR) endophytic bacteria Serratia sp. IU01 (Ullah et al., 2019). Plants were exposed to cadmium stress@1000 mg/100ml \& 2000mg/100ml of cadmium nitrate $\left(\mathrm{Cd}\left(\mathrm{NO}_{3}\right)_{2}\right)$ and endophytic microbial interaction with Serratia $s p$. IU01 for four weeks. In case of genotype Abasyn-95, three weeks old seedlings were exposed to cadmium stress @ $1000 \mathrm{mg} / 100 \mathrm{ml}$ for three weeks. At the end of each experiment, fresh weight was measured, and these were then allowed to dry in the oven for two days at $80^{\circ} \mathrm{C}$. The dry weight recorded.

Determination of thiol contents: Leaf samples were crushed with the help of mortar and Pestle in liquid nitrogen into powdered form. Approximately $100 \mathrm{mg}$ of powdered leaf material was used for the extraction of thiols in $1000 \mu \mathrm{l}$ of $0.1 \mathrm{~N} \mathrm{HCl}$. From this acidic extract, $25 \mu \mathrm{l}$ were added to the reducing mixture containing 190 $\mu \mathrm{l} \mathrm{ddH}_{2} \mathrm{O}, 20 \mu \mathrm{l} 20 \mathrm{mM}$ Tris $\mathrm{pH} 8.3,10 \mu \mathrm{l}$ of $10 \mathrm{mM}$ DTT and $25 \mu \mathrm{l}$ of $0.08 \mathrm{mM} \mathrm{NaOH}$. Thiols in the samples were reduced by incubation of this mixture in the dark for 1 hour. Monobromobimane (MBB) dye was added to conjugate the reduced sulfhydryl group of metabolites with the fluorescent dye. After the addition of MBB, the samples were kept in the dark for 15 minutes. After 15 minutes incubation, $5 \%$ acetic acid $(705 \mu \mathrm{l})$ was added to thiol-bimane derivatives for the stabilization, and the derivatives were separated by high performance liquid chromatography (HPLC) (Waters Alliance e2695 Separations Module), Nova Pak C18 column $4.6 \times$ $250 \mathrm{~mm}$,). Thiols were detected and isolated, as described previously (Khan et al., 2010). Empower 3 software (Waters, USA) was used for the analysis and quantification of the data.

Determination of cadmium contents via atomic absorption spectrophotometry: The leaves and roots tissue of the plants were dried at $80{ }^{\circ} \mathrm{C}$ for $48 \mathrm{hrs}$ in an oven. This material was then weighed to $200 \mathrm{mg}$ and digested by nitric acid, as describes by Zarcinas et al. (1987). To determine the elemental concentration of each of the digests atomic absorption spectrophotometer was used.

Statistical analysis: The Statistical analyses were carried out using SigmaPlot 12.5 (Systat Inc., USA). Different data sets were analyzed for statistical significance with the One-way Repeated Measures Analysis of Variance, which uses the Holm-Sidak method for all pairwise multiple comparisons (Holm, 1979). Normality distribution of data points was tested with the ShapiroWilk (Shapiro and Wilk, 1965) method ( $\mathrm{p}$ to reject was $\mathrm{p}>0.05)$. Letters indicate a significant difference $(\mathrm{P}<$ $0.05)$ in the figures.

\section{RESULTS AND DISCUSSION}

Effect of cadmium stress on the biomass of Brassica napus L. genotypes under different growth regimes: Heavy metal tolerance and growth promoting properties of an endophytic bacterial species, i.e., Serratia sp. IU01 isolated from Solanum nigrum L. have been recently 
reported in Brassica juncea (Ullah et al., 2019). In order to investigate whether Serratia sp. IU01 can also provide a physiological advantage in terms of enhanced growth and cadmium tolerance in a different Brassica species, i.e., Brassica napus L., cadmium was co-applied with Serratia sp. IU01 to two different Brassica napus L. genotypes in independent experiments. Inoculation of the three weeks old Abasyn-95 genotype on autoclaved soil with Serratia $s p$. IU01 under cadmium stress for three weeks significantly increased the biomass of inoculated plants compared to sole cadmium treated and control plants (Fig. 1C). In an independent experiment, inoculation of one week old seedlings of Brassica napus genotype NIFA-1 on autoclaved soil with Serratia $s p$. IU01 under the same dose of cadmium and doubled dose of cadmium stress showed a similar pattern of increased biomass for inoculated plants compared to sole cadmium treated and controlled plants (Fig. 1B \& C). However, unlike Abasyn-95, the genotype NIFA-1, under these experimental conditions didn't show any signs of cadmium sensitivity in terms of biomass reduction after cadmium stress as indicated by the non-significant differences between the biomass of the controlled and cadmium treated NIFA-1 plants. Although other possibilities, such as buffering of the effective cadmium concentration in the sand culture, could not be ruled out, the observed discrepancies between these two genotypes of Brassica napus could most likely be attributed to genotypic differences. The endophytes that colonize the internal plant tissues form inevitable constituents of the plants' internal ecosystem and many studies in the recent past have reported their potential in plant growth promotion and metal tolerance and accumulation (Khan et al., 2015; Yasin et al., 2015a,b; Ullah et al., 2019).
Earlier work on the entophytic bacterial species, i.e., Serratia sp. IU01, isolated from Solanum nigrum L., has demonstrated the role of this endophyte in stimulating plant growth and cadmium tolerance in Brassica juncea (Ullah et al., 2019). The current study demonstrated the potential of Serratia sp. IU01 in terms of plant growth promotion and cadmium detoxification and tolerance in Brassica napus. These results are similar to the recent reports where a significant increase in the biomass of Brassica juncea was observed after inoculation of the same bacterial endophyte (Ullah et al., 2019). The increase in biomass has been attributed to the ability of the endophytes to synthesize phytohormones such as gibberellins, IAA, and cytokinins in previous studies (You et al., 2013; Khan et al., 2014). It has been shown that in Brassica juncea, the same isolate, i.e., Serratia sp. IU01 produced phytohormone IAA, which has been reported to facilitate plant growth parameters such as roots/shoots' length and biomass (Khan et al., 2015). The effectiveness of several bacterial strains, such as Azomonas sp. RJ4, Xanthomonas sp. RJ3, Pseudomonas $s p$. RJ10, Bacillus sp. RJ31 and Bacillus sp. RJ16 in promoting plant growth in two important Brassicaceae crops, i.e., B. napus and $B$. juncea have been demonstrated in several studies (Mata et al., 2002; Sheng et al., 2008; Ma et al., 2013). Cadmium is toxic to the plants even at low concentrations, and it causes a reduction in the biomass of the plants in several plant species. It causes chlorophyll degradation, which leads to inhibition of photosynthesis (Sun et al., 2007; Gallego et al., 2012; Hossain et al., 2012). Heavy metals can be detoxified by specific entophytic microbes via several mechanisms, including immobilization and accumulation (Haferburg and Kothe, 2007).
(A)

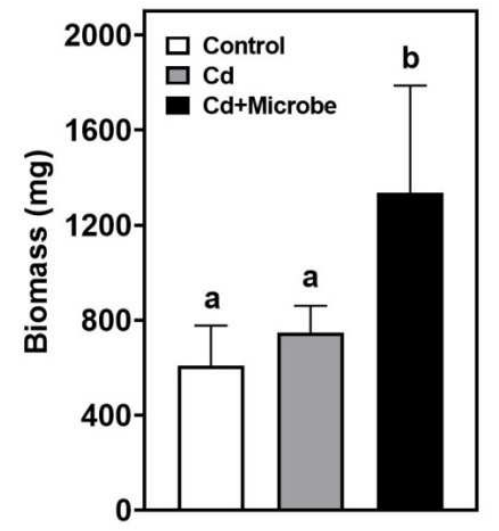

(B)

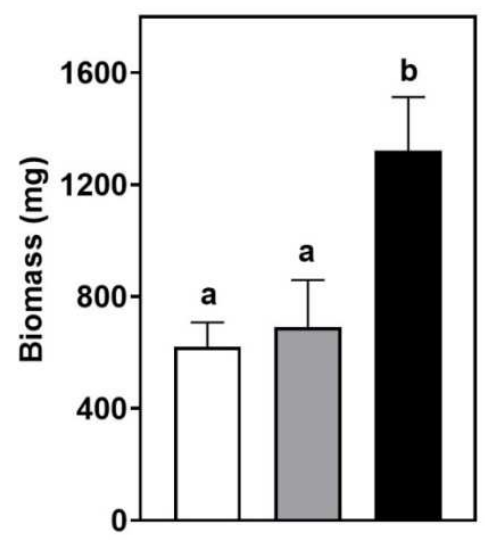

(C)

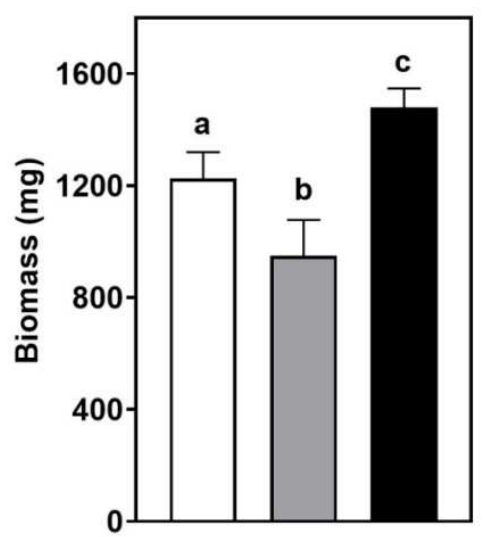

Figure 1: Effect of cadmium stress and endophytic bacteria on the biomass of Brassica napus genotypes.

Biomass of NIFA-1 exposed to cadmium stress @ $1000 \mathrm{mg} / 100 \mathrm{ml}$ (A) and @ 2000 mg/100ml (B) for four weeks. Biomass of Abasyn-95 exposed to cadmium stress@1000 mg/100ml (C) for three weeks. Bars 
indicate biological replicates; $n \geq 3$. Letters indicate statistically significant differences between groups determined with the one-way ANOVA test $(\mathrm{P}<0.05)$. Values represent means \pm standard deviation (SD).

Effect of cadmium and microbes on cysteine and glutathione contents of Brassica napus plants: Due to the redox-active thiol, glutathione is a very versatile biomolecule in defense of plants against oxidative stress (Russo et al., 1995; Sánchez-Fernández et al., 1997). To investigate the impact of cadmium induced oxidative stress on the steady-state levels of glutathione and cysteine; a rate liming precursor of glutathione (Strohm et al., 1995; Noctor et al., 1996), HPLC analysis were carried out for the shoots' samples of the control and cadmium treated plants in the presence and absence of Serratia $s p$. IU01. HPLC analysis revealed a significant increase in the steady-state levels of cysteine and glutathione in cadmium treated Abasyn-95 plants compared to untreated plants (Fig. 2C \& F). However, inoculation of Abasyn-95 with Serratia sp. IU01 significantly reduced the cysteine and glutathione contents in cadmium exposed plants compared to sole cadmium treated plants. There was no significant difference between cadmium treated plants inoculated with Serratia sp. IU01 and untreated controlled plants in terms of cysteine and glutathione contents. However, in an independent experiment, exposure of genotype NIFA1 to the same concentration of cadmium for three weeks did not cause any significant changes in the cysteine and glutathione contents of controlled, cadmium treated and Serratia sp. IU01 inoculated cadmium treated plants (Fig. 2A \& D). So in the next experimental setup, cadmium concentration was doubled from $1000 \mathrm{mg} / 100 \mathrm{ml}$ to $2000 \mathrm{mg} / 100 \mathrm{ml}$. Exposure of NIFA-1 plants to the higher concentration of cadmium for three weeks led to a significant increase in the cysteine and glutathione contents of cadmium stressed plants (Fig. 2B \& E). Similar to the genotype Abasyn-95, inoculation of NIFA1 with Serratia sp. IU01 led to a significant reduction in the cysteine and glutathione levels of cadmium treated plants. The levels of cysteine and glutathione in the inoculated plants were similar to the levels of the untreated controlled plants.

In order to cope with the cadmium induced oxidative damage that results in the production of reactive oxygen species (ROS), plants have evolved different mechanisms to deal with the situation. These include the production of various kinds of enzymatic and non-enzymatic antioxidants that avert ROS accumulation and mitigate the oxidative damage (Khan et al., 2013). Glutathione is one of the very most important antioxidants in the cell that play a key role in the protection of plants against the various form of biotic and abiotic stresses (Cobbett and Goldsbrough, 2002; Clemens 2006; Tripathi et al., 2012). Like the plant cells, endophytic bacteria are capable of producing similar antioxidants that are released in the host environment. The addition of exogenous antioxidants such as glutathione by endophytic bacteria helps boost the defense potential of the plants by averting ROS accumulation. Our results regarding elevated glutathione contents in the sole cadmium treated plants and reduced glutathione contents in the cadmium treated plants inoculated with Serratia sp. IU01 corroborate the findings of the previous reports (Ullah et al., 2019) and do suggest that the application of microbes produced antioxidants such as glutathione, which in line with the proposed function of glutathione, have scavenged the ROS produced in the plants' tissues. Our data in this regard is also in line with the previous reports where exogenous sources of antioxidants have been demonstrated to reduce the magnitude of the stressor, which helps in decreasing the plant's innate immune response (Brader et al., 2014). Endophytic bacteria can further boost up defense potential of the plant by releasing exogenous enzymatic and non-enzymatic antioxidants that avert ROS accumulation and mitigate the oxidative damage (Khan et al., 2013). The production of several antioxidants by plants as well as by endophytes, supports the plants under stressed conditions and detoxifies the heavy metals by the so-called processes of bioaccumulation and bio-sorption (Mosa et al., 2016).

Effect of cadmium stress on cadmium accumulation in inoculated and un-inoculated Abasyn-95 Brassica napus plants: The cadmium accumulation was analyzed using atomic absorption spectrophotometer. Exposure of Abasyn-95 plants for three weeks to cadmium stress revealed that cadmium treated and Serratia sp. IU01 inoculated cadmium treated plants accumulated significantly higher cadmium concentration compared to the control plants (Fig. 3). There was no statistical difference between the cadmium treated and Serratia $s p$. IU01 inoculated cadmium treated plants in terms of per unit mass cadmium accumulation but keeping in view the significantly higher biomass of the Serratia sp. IU01 inoculated cadmium treated plants compared to sole cadmium treated plants (Fig. 1C), the increased biomass of bacterial inoculated plants provide more space for cadmium accumulation and detoxification (Khan et al., 2015) per plants basis compared to un-inoculated cadmium treated plants. 
(A)

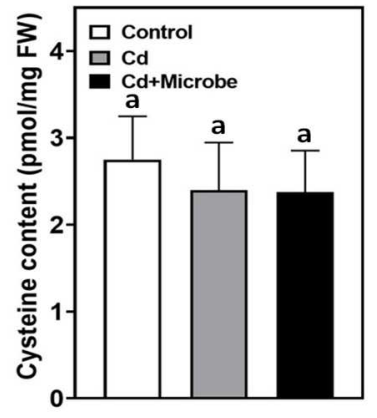

(D)

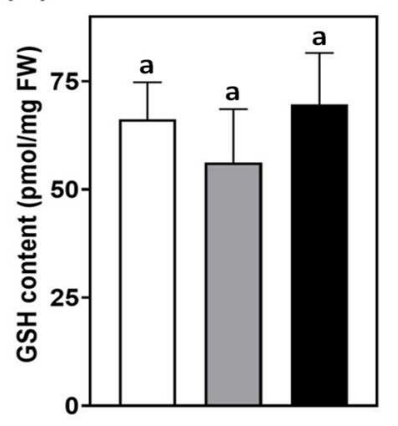

(B)

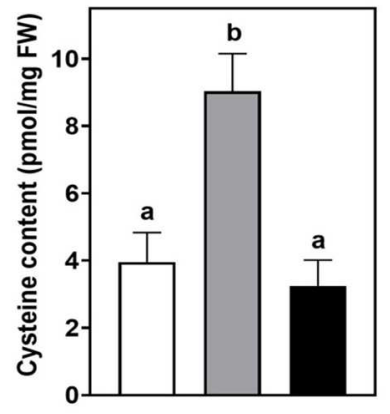

(E)

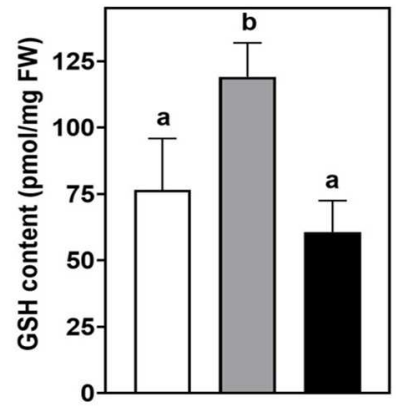

(C)

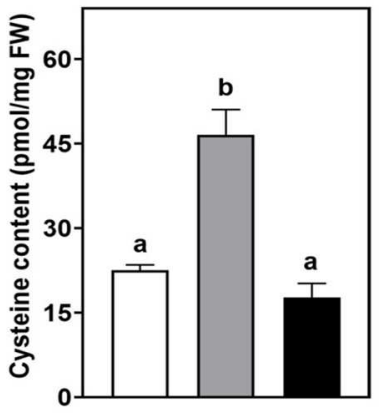

(F)

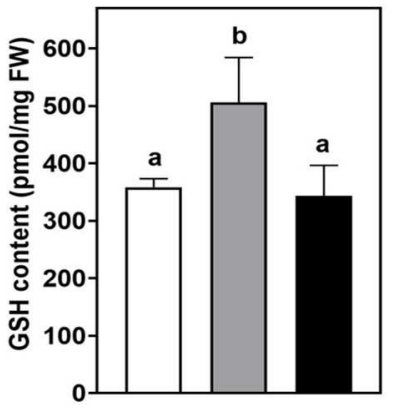

Figure 2: Effect of cadmium stress and endophytic bacteria on the thiols contents of Brassica napus genotypes. Cysteine contents in the shoots samples of NIFA-1 exposed to cadmium stress @ $1000 \mathrm{mg} / 100 \mathrm{ml}$ (A) and @ 2000 $\mathrm{mg} / 100 \mathrm{ml}$ (B) for four weeks. Cysteine contents in the shoots samples of Abasyn-95 exposed to cadmium stress @ 1000 $\mathrm{mg} / 100 \mathrm{ml}$ (C) for three weeks. Glutathione contents in the shoots samples of NIFA-1 exposed to cadmium stress @, $1000 \mathrm{mg} / 100 \mathrm{ml}$ (D) and @ $2000 \mathrm{mg} / 100 \mathrm{ml}$ (E) for four weeks. Glutathione contents in the shoots samples of Abasyn-95 exposed to cadmium stress @ $1000 \mathrm{mg} / 100 \mathrm{ml}$ (F) for three weeks. Bars indicate biological replicates; $n \geq 3$. Letters indicate statistically significant differences between groups determined with the one-way ANOVA test $(\mathrm{P}<0.05)$. Values represent means \pm standard deviation (SD).

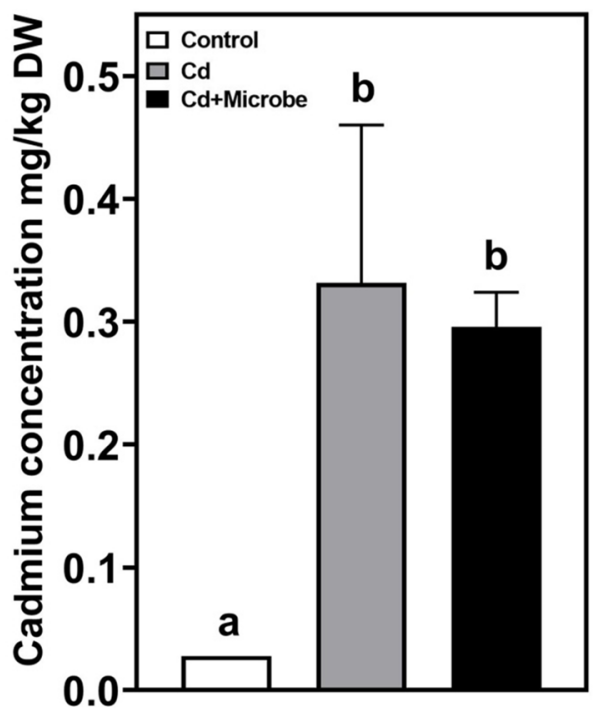

Figure 3: Cadmium accumulation in the cadmium treated and Serratia sp. IU01 inoculated Abasyn-95 genotype. Cadmium contents in the shoots of Abasyn-95 exposed to cadmium stress @ 1000 mg/100ml for three weeks. Bars indicate biological replicates; $n \geq 3$. Letters indicate statistically significant differences between groups determined with the one-way ANOVA test $(\mathrm{P}<0.05)$. Values represent means \pm standard deviation (SD). 
Acknowledgments: We thankfully acknowledge the Higher Education Commission (HEC) of Pakistan for funding part of this project. We gratefully acknowledge Dr. Ihsan Ullah, Assistant Professor, Department of Biological Sciences, King Abdul-Aziz University, Saudi Arabia, for his contribution to the manuscript and for providing the bacterial strain, i.e., Serratia sp. IU01 that was used in this study.

\section{REFERENCES}

Angelova, V., R. Ivanova, J. Todorov, and K. Ivanov (2017). Potential of rapeseed (Brassica napus L.) for phytoremediation of soils contaminated with heavy metals. J. Environ. Prot Ecol, 18: 468-478.

Benavides, M. P., S. M. Gallego and M. L. Tomaro (2005). Cadmium toxicity in plants. Braz. J. Plant Physiol. 17(1): 21-34.

Brader, G., S. Compant, B. Mitter, F. Trognitz and A. Sessitsch (2014). Metabolic potential of endophytic bacteria. Curr. Opin. Biotechnol. 27(1): 30-37.

Cahoon, D. R. (2015). Estimating relative sea-level rise and submergence potential at a coastal wetland. Estuaries Coasts 38(3): 1077-1084.

Chen, L., S. Luo, X. Xiao, H. Guo, J. Chen, Y. Wan, B. Li, T. Xu, Q. Xi and C. Rao (2010). Application of plant growth-promoting endophytes (PGPE) isolated from Solanum nigrum $L$. for phytoextraction of Cd-polluted soils. Appl. soil Ecol. 46(3): 383-389.

Chen, L., S. Luo, X. Li, Y. Wan, J. Chen and C. Liu (2014). Interaction of Cd-hyperaccumulator Solanum nigrum $L$. and functional endophyte Pseudomonas sp. Lk9 on soil heavy metals uptake. Soil Biol. Biochem. 68(1): 300-308.

Clemens, S. (2006). Evolution and function of phytochelatin synthases. J. Plant Physiol. 163(3): 319-332.

Cobbett, C., and P. Goldsbrough (2002). Phytochelatins and metallothioneins: roles in heavy metal detoxification and homeostasis. Annu. Rev. Plant Biol. 53(1): 159-182.

Di Fiore, S., and M. Del Gallo (1995) Endophytic bacteria: their possible role in the host plant, pp. 169-187 in Azospirillum VI and related microorganisms. Springer.

Dudeja, S., R. Giri, R. Saini, P. Suneja-Madan and E. Kothe (2012). Interaction of endophytic microbes with legumes. J Basic Microbiol. 52(3): 248-260.

Gairola, C., G. Wagner and J. Diana (1992). Tobacco, Cd and health. J. Smoking-related disorders, 3(1): 3-6.
Gallego, S. M., L. B. Pena, R. A. Barcia, C. E. Azpilicueta, M. F. Iannone, E. P. Rosales, M. S. Zawoznik, M. D. Groppa and M. P. Benavides (2012). Unravelling cadmium toxicity and tolerance in plants: insight into regulatory mechanisms. Environ. Exp. Bot. 83(3): 33-46.

Gratão, P. L., A. Polle, P. J. Lea and R. A. Azevedo (2005). Making the life of heavy metal-stressed plants a little easier. Funct. Plant Biol. 32(6): 481-494.

Haferburg, G., and E. Kothe (2007). Microbes and metals: interactions in the environment. J. Basic Microbiol. 47(6): 453-467.

Holm, S. (1979). A simple sequentially rejective multiple test procedure. Scand. J. Stat. 6 (2): 65-70.

Hossain, M. A., P. Piyatida, J. A. T. da Silva and M. Fujita (2012). Molecular mechanism of heavy metal toxicity and tolerance in plants: central role of glutathione in detoxification of reactive oxygen species and methylglyoxal and in heavy metal chelation. J. Bot. 2012: 37.

Khan, M. S., F. H. Haas, A. A. Samami, A. M. Gholami, A. Bauer, K. Fellenberg, M. Reichelt, R. Hänsch, R. R. Mendel and A. J. Meyer (2010). Sulfite reductase defines a newly discovered bottleneck for assimilatory sulfate reduction and is essential for growth and development in Arabidopsis thaliana. Plant Cell 22 (4): 12161231.

Khan, A. L., M. Waqas, M. Hamayun, A. Al-Harrasi, A. Al-Rawahi and I.-J. Lee (2013). Co-synergism of endophyte Penicillium resedanum LK6 with salicylic acid helped Capsicum annuum in biomass recovery and osmotic stress mitigation. BMC Microbiol. 13(1): 51.

Khan, A. R., I. Ullah, A. L. Khan, S.-J. Hong, M. Waqas, G.-S. Park, Y. Kwak, J. Choi, B.-K. Jung and M. Park (2014). Phytostabilization and physicochemical responses of Korean ecotype Solanum nigrum $L$. to cadmium contamination. Water Air Soil Pollut. 225(10): 2147.

Khan, A. R., I. Ullah, A. L. Khan, G.-S. Park, M. Waqas, S.-J. Hong, B. K. Jung, Y. Kwak, I.-J. Lee and J.-H. Shin (2015). Improvement in phytoremediation potential of Solanum nigrum under cadmium contamination through endophytic-assisted Serratia sp. RSC-14 inoculation. Environ. Sci. Pollut. Res. Int. 22(18): 14032-14042.

Lehtonen, P. T., M. Helander, S. A. Siddiqui, K. Lehto and K. Saikkonen (2006). Endophytic fungus decreases plant virus infections in meadow ryegrass (Lolium pratense). Biol. Lett. 2(4): 620-623.

Ma, Y., M. Rajkumar, Y. Luo and H. Freitas (2013). Phytoextraction of heavy metal polluted soils 
using Sedum plumbizincicola inoculated with metal mobilizing Phyllobacterium myrsinacearum RC6b. Chemosphere, 93(7): 1386-1392.

Mata, J. A., J. Martínez-Cánovas, E. Quesada and V. Béjar (2002). A detailed phenotypic characterisation of the type strains of Halomonas species. Syst. Appl. Microbiol. 25(3): 360-375.

Mazess, R. B., and H. S. Barden (1991). Bone density in premenopausal women: effects of age, dietary intake, physical activity, smoking, and birthcontrol pills. Am. J. Clin. Nutr. 53(1): 132-142.

Mosa, K. A., I. Saadoun, K. Kumar, M. Helmy and O. P. Dhankher (2016). Potential biotechnological strategies for the cleanup of heavy metals and metalloids. Front. Plant sci. 7: 303.

Noctor, G., M. Strohm, L. Jouanin, K.-J. Kunert, C. H. Foyer and H. Rennenberg (1996). Synthesis of glutathione in leaves of transgenic poplar overexpressing [gamma]-glutamylcysteine synthetase. Plant Physiol. 112(3): 1071-1078.

Russo, T., N. Zambrano, F. Esposito, R. Ammendola, F. Cimino, M. Fiscella, J. Jackman, P. M. O'Connor, C. W. Anderson and E. Appella (1995). A p53-independent pathway for activation of WAF1/CIP1 expression following oxidative stress. J. Biol. Chem. 270(49): 2938629391.

Ryan, J. A., H. R. Pahren and J. B. Lucas (1982). Controlling cadmium in the human food chain: a review and rationale based on health effects. Environ. Res. 28(2): 251-302.

Sánchez-Fernández, R., M. Fricker, L. B. Corben, N. S. White, N. Sheard, C. J. Leaver, M. Van Montagu, D. Inzé and M. J. May (1997). Cell proliferation and hair tip growth in the Arabidopsis root are under mechanistically different forms of redox control. Proc. Nat. Acad. Sci. 94(6): 2745-2750.

Shapiro, S. S., and M. B. Wilk (1965). An analysis of variance test for normality (complete samples). Biometrika 52: 591-611.

Sheng, X.-F., J.-J. Xia, C.-Y. Jiang, L.-Y. He and M. Qian (2008). Characterization of heavy metalresistant endophytic bacteria from rape (Brassica napus) roots and their potential in promoting the growth and lead accumulation of rape. Environ. Pollut. 156(3): 1164-1170.

Strohm, M., L. Jouanin, K. J. Kunert, C. Pruvost, A. Polle, C. H. Foyer and H. Rennenberg (1995). Regulation of glutathione synthesis in leaves of transgenic poplar (Populus tremula $x$ P. alba) overexpressing glutathione synthetase. Plant J. 7(1): 141-145.
Sun, R.-L., Q.-X. Zhou, F.-H. Sun and C.-X. Jin (2007). Antioxidative defense and proline/phytochelatin accumulation in a newly discovered Cdhyperaccumulator, Solanum nigrum L. Environ. Exp. Bot. 60(3): 468-476.

Tripathi, R. D., P. Tripathi, S. Dwivedi, S. Dubey and D. Chakrabarty (2012). Arsenomics: omics of arsenic metabolism in plants. Front. Physiol. 3: 275.

Ullah, I., B. O. Al-Johny, K. M. AL-Ghamdi, H. A. AlZahrani, Y. Anwar, A. Firoz, A.-K. Naser and M. A. A. Almatry (2019). Endophytic bacteria isolated from Solanum nigrum L., alleviate cadmium (Cd) stress response by their antioxidant potentials, including SOD synthesis by sodA gene. Ecotoxicol. Environ. Saf. 174: 197-207.

Vinichuk, M., A. Mårtensson, T. Ericsson and K. Rosén (2013). Effect of arbuscular mycorrhizal (AM) fungi on $137 \mathrm{Cs}$ uptake by plants grown on different soils. J. Environ. Radioact. 115: 151156.

White, P., and P. Brown (2010). Plant nutrition for sustainable development and global health. Annals Bot. 105(7): 1073-1080.

Xiao, X., S. Luo, G. Zeng, W. Wei, Y. Wan, L. Chen, H. Guo, Z. Cao, L. Yang and J. Chen (2010). Biosorption of cadmium by endophytic fungus (EF) Microsphaeropsis sp. LSE10 isolated from cadmium hyperaccumulator Solanum nigrum L. Bioresour. Technol. 101(6): 1668-1674.

Yasin, M., A. F. El-Mehdawi, A. Anwar, E. A. PilonSmits and M. Faisal (2015a). Microbialenhanced selenium and iron biofortification of wheat (Triticum aestivum L.)-applications in phytoremediation and biofortification. Int. J. Phytoremediat. 17(4): 341-347.

Yasin, M., A. F. El Mehdawi, C. E. Jahn, A. Anwar, M. F. Turner, M. Faisal and E. A. Pilon-Smits (2015b). Seleniferous soils as a source for production of selenium-enriched foods and potential of bacteria to enhance plant selenium uptake. Plant Soil. 386(1-2): 385-394.

You, Y. H., H. Yoon, S. M. Kang, J. R. Woo, Y. S. Choo, I. J. Lee, J. H. Shin and J. G. Kim (2013). Cadophora malorum $\mathrm{Cs}-8-1$ as a new fungal strain producing gibberellins isolated from Calystegia soldanella. J. Basic Microbiol. 53(7): 630-634.

Zarcinas, B., B. Cartwright and L. Spouncer (1987). Nitric acid digestion and multi-element analysis of plant material by inductively coupled plasma spectrometry. Commun. Soil Sci. Plant Anal. 18(1): 131-146. 